\title{
DIGITAL STORYTELLING: STUDENT VULNERABILITY DURING THE PROCESS AND ITS IMPACT ON TEACHING AND LEARNING ONE YEAR LATER
}

\author{
Heather N. Phillips, Janet Condy and Chantyclaire Tiba \\ Cape Peninsula University of Technology \\ P O Box 652, Cape Town 8000, South Africa
}

\begin{abstract}
Digital storytelling (DST) is described as 'the modern expression of the ancient art of storytelling' with one of its categories focusing on personal narratives in which authors tell their own personal stories about significant experiences in their lives. The imperative to tap into our students' social-emotional learning through DST and creating a trauma-sensitive school culture is at the forefront of pedagogical conversations today. The DST process allowed pre-service teachers to take risks, risks of self-disclosure, risks of change, risks of not knowing, all of which rendered them vulnerable, resulting in deepened learning. The findings indicate that the process motivated newly qualified teachers to reflect on their own development, their practice and student learning through the lens of human connections, lived curriculum, self-reflection. They learnt the true value of social interaction and student engagement.
\end{abstract}

\section{KEYWORDS}

Digital Storytelling, Vulnerability, Pedagogy, Re-Humanization, Lived Experience, Reflection

\section{INTRODUCTION}

'Stop moments' in our lives describe not only the 'emerging openings' we experience that shape and shift the direction of our lives but also allow ourselves to be shaped by it. It includes being prepared to 'labour, risk, learn and play with possibilities that could interrupt the normative ways of doing things' (Rodricks: 2018).

Digital storytelling (DST) provides those 'stop moments' where a 'voice' is given to students as an opportunity for self-expression. Xu, et al. (2011) describes storytelling to be a natural method of communicating with others in our daily social interactions. DST, however, is described by The Digital storytelling Association (2002) as 'the modern expression of the ancient art of storytelling' with one of its categories focusing on personal narratives in which authors tell their own personal stories about significant experiences in their lives (Robin, 2008: 224).

These personal stories can overstep boundaries which can render teachers vulnerable in their daily task of teaching. The emotional dimension of vulnerability can develop, within teachers, feelings of negativity, frustration, guilt, anger and even fear which will impact the teaching and learning situation since education has and always will be powered by human connection. However, this emotional dimension can also be both a strength and an essential pillar of learning.

\section{LITERATURE REVIEW AND THEORETICAL FRAMWORK}

\subsection{A Pedagogy of Vulnerability}

This study is nestled within a theoretical framework of a pedagogy of vulnerability. Pedagogy of vulnerability is, according to Brantmeier (2013: 3), 'an approach to education that invites vulnerability and deepened learning through a process of self and mutual disclosure on the part of co-learners in a classroom'. 
A dictionary description of being vulnerable is: capable of being wounded or injured; open to attack; and sensitive to or affected by certain influences (Turner, 2006). To further conceptualize vulnerability we draw on definitions provided by Hooks, Brown and Kelchtermans. Brown (2015:34) defines vulnerability as 'uncertainty, risk and emotional exposure'. These descriptions conjure up images of negativity and weakness.

Brown (2015) however, affirms that being vulnerable is not about winning or losing; it's being courageous enough to show up and be seen when we are unsure and have no control over the outcome. 'Vulnerability is not weakness; it's our greatest measure of courage'. Hooks (2010) outlines vulnerability to be a process of empowerment, a place of mutual openness where learners are encouraged to take risks. Kelchtermans (2009), however, argues that when referring to vulnerability we are not making reference to a mood or emotion but rather to understand vulnerability as structural and, therefore, as an inherent condition of the teaching profession. The pedagogy of vulnerability allows for voices to be heard and validated in formal school settings. It is a pedagogy that is relevant, especially for teachers who want to contribute to current school climates positively.

The pedagogy of vulnerability 'is guided by a willingness to meet our students where they are. This is a process that does not happen overnight, but one that involves building trust over the course of the semester by taking the time to learn what matters to our students, both inside and outside the classroom' (Mershon, 2018), bearing in mind that being vulnerable means that you are capable of being hurt.

\subsection{Digital Storytelling and Pedagogy}

'The imperative to tap into our students' social-emotional learning and create a trauma-sensitive school culture is at the forefront of pedagogical conversations' (Dukes, 2018). The DST technique is one mode that can be used to create a platform for students to journey through their own social-emotional arena. Gachago (2015) contends that the DST 'originates directly from participants lived experiences'. This technique allows students to "combine the art of telling stories with multimedia objects such as images, audio, video, text, graphics and music' (Rossier \& Garcia, 2010:37b). Robin (2008:224-228) discusses one category of DST as the opportunity to create and share personal narratives of significant experiences from various episodes in their lives, hence the process can be extremely emotional.

Zembylas (2011) argues that in teaching and learning emotions are regarded as being 'internal states of being' and should remain individual and private so that sentimentality can be avoided. This sentimentality or newly found sensitivity taught pre-service teachers that whether you were a teacher or a learner, whether your backgrounds were diverse, all the stories were similar (Condy, 2015). Ultimately the DST process allowed pre-service teachers to take risks, 'risks of self-disclosure, risks of change, risks of not knowing', all of which rendered them vulnerable, resulting in deepened learning (Brantmeier, 2013).

Robin (2008: 224-228)) continues to discuss the benefits of DST to include:

- It supports learner-centred activites;

- $\quad$ Promotes multiple skills in learners;

- $\quad$ Gives a voice to struggling learners; and

- Encourages deep reflection.

Similarly, Barret (2005) makes reference to the convergence of four learner-centred strategies that are enhanced through DST.

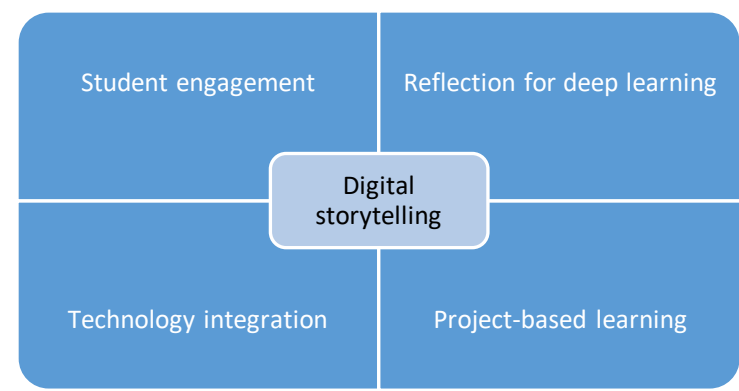

Figure 1. Convergence of four learner-centred strategies (Source: Barret, 2005) 
Both Robin (2008) and Barret (2005) purport the significance of using DST as a pedagogical tool, 'to define and explore the 'promise and the pain of a pedagogy of vulnerability, exploring how and when sharing their stories can deepen learning' (Brantmeier, 2013; 2). This deepened learning, Brantmeier (2013) explains, is learning that 'allows for flexibility and responsiveness and it is learning that endures over time'.

\subsection{Overstepping the Boundaries}

Vulnerability has for many been seen as a sign of weakness. People work hard to hide their vulnerability behind a mask - if you are embarrassed or hurt, you show aggravation; if you are scared or disappointed, you show indifference, if you secretly really like someone, you show contempt...otherwise you are regarded as desperate and pathetic. We buy into the notion that hostility proves strength and vulnerability weakness, and that 'independence and invulnerability are synonymous with power and success' (Straka, 2018). However, to be vulnerable is to be courageous since the focus is on facing your imperfections, facing your authentic self rather than hiding behind a mask.

In accepting our authentic selves we are able to face others and we are able to work from a 'place of mutual openness rather than from an attitude of defensiveness'. Hooks (1994) argues that 'a holistic model of learning will also be a place where teachers grow, and are empowered by the process. That empowerment cannot happen if we refuse to be vulnerable while encouraging students to take risks...'. Lasky (2005) agrees and views this vulnerability as the 'chosen behaviour' for teachers.

Mershon (2018), however stresses that we cannot overstep the boundaries and we need to 'hold ourselves to the same standards we hold our students'. Through the pedagogy of vulnerability we must develop a strong sense of trust (Brown, 2015) between teacher and student, for this trust is not only the 'lubricant of thriving societies (Delhey, et al. 2011:787), but also 'the keystone of successful personal relations' (Forsyth, et al. 2011:3). However, Brown (2015) argues that this vulnerability must be based on mutuality and must respect boundaries. She further relates that 'imperfections are not inadequacies; they are reminders that we're all in this together'.

\subsection{The Power of Human Connection}

In overstepping our boundaries and creating safe spaces for teaching and learning through the development of strong bonds of trust and respect, we can generate 'deep meaningful connections with self and others' (Straka, 2018). She further stresses that these connections are paramount, both in our development as human beings and in teaching and learning where it is especially critical.

Palmer (1998:17) states that teaching 'is a daily exercise in vulnerability' for it is the way 'teachers live in their jobs'. This translates into a lived curriculum which refers to the content of our lives and our past life experiences which, according to Straka (2018) is the basis of all new learnings. She explains that great learning benefits can be derived from classrooms where lived experience is as important as academic curriculum. These, nestled in a framework of vulnerability, becomes engagement of learning about life itself.

Connecting with vulnerability is a humanizing pedagogy which is 'directed by compassion, care, respect and love for students and teachers, and their identities, histories and experiences' (Keet, Zinn \& Porteus, 2009). However it is argued that 'there is an art to disclosure' (Keet, et al, 2009:11) which requires careful judgement. Considering learners and their experiences of possible past trauma and emotional pain is paramount if we do not want them to experience further rejection in the classroom. Re-humanizing vulnerability requires a greater awareness on the part of the teacher and the student in order to eliminate these possible risks.

To protect learners from the pain of rejection or relived trauma during disclosure, and keep their learning space safe, there is a need for constant self-reflection on the part of teachers. Self-reflection is a process of self-examination and self-assessment deliberately effected to improve professional practice (Shandamo, 2010). Brookfield (2004) argues that without reflection, teachers run the continual risk of making poor decisions and bad judgments. This is substantiated by Squires (1999: 16):

Most professional problems are messy and inchoate... they require a continuous process of reflection on what is happening and what has happened (reflection in action and reflection on action). Such a process can improve the quality of decisions and is contrasted with unreflective, unthinking routine, or habit driven behavior. 
In many learning contexts, the pedagogy of vulnerability becomes very relevant to teachers for the practice of co-learning. Within this practice we need to build trust and promote critical self-reflection where the assumptions of one's views, values and behavior can be questioned. Brantmeier (2013:4) refers to this critical self-reflection as a 'contemplative practice of examining the origination of one's own worldview and gently, kindly scrutinizing that worldview with comparative and contrasting frames of reference'.

\subsection{Vulnerability and Teaching and Learning}

Kelchtermans (2009) promotes teachers to consider, more seriously, teaching with vulnerability since it could lead to greater teacher resilience. Greater teacher resilience translates into "better equipped teachers to be in connection with themselves and their students, creating the necessary conditions for meaningful learning to take place'. Kohan and Turpin (2014) illustrates the link between Kegan's (1982, 1995) concept of disequilibrium and Dewey's (1993, 1989) concept of 'felt difficulty' and argues that 'in order for transformative learning to occur, one may have to "lose balance" or experience disequilibrium. One can surely argue that vulnerability does not automatically lead to deep learning but undergoes many reflective processes in which a 'disequilibrium' or 'felt difficulty' is experienced before transformation can take place.

For deep learning to occur it is important to develop strategies that will foster a resilient mindset to eliminate the possibility of students putting up barriers to positive development of teacher-student interactions. The following strategies will reinforce a positive mindset within the framework of a pedagogy of vulnerability. Teachers should

- Understand the lifelong impact they have on students, including instilling a sense of hope and resilience;

- Believe that the learning that occurs in the classroom and the behavior exhibited by students has as much, if not more, to do with the influence of teachers than what students might bring into the situation;

- Believe that attending to the social-emotional needs of students is not an "extra curriculum" that draws time away from teaching academic subjects;

- Recognize that if educators are to effectively relate to students, they must be empathic, always attempting to perceive the world through the eyes of the student;

- Appreciate that the foundation for successful learning and a safe and secure classroom climate is the relationship that teachers forge with students; and

- Realize that one of the greatest obstacles to learning is the fear of making mistakes and feeling embarrassed or humiliated

Brantmeier (2013:3) refers to the pedagogy of vulnerability as a transformative pedagogy which assists in the actualization of goals for a higher education. Transformative pedagogies are the vehicles to deeper learning and 'holds the potential for self-transformation, self-growth and social change.

Unless we are able to embrace our vulnerability we will not reach our full potential. All we will do is to build walls that will constantly prevent us from understanding or being understood.

\section{METHODOLOGY}

An interpretivist, qualitative research approach was followed in this study. Data was collected through:

- $\quad$ Digital stories conducted in 2017 and 2018 and

- $\quad$ Focus group interviews, based on the digital stories, conducted in 2019.

Four newly qualified teachers (NQT's), purposively sampled, took part in the 90 minute focus group interview in order to elicit how they experienced the process of creating their digital stories as pre-service students as well as how this experience impacted their teaching one year later. Since the engagement was one of sharing and listening to each other's digital stories, it was thought best to keep the group small to allow a safe space for participants to reflect on their emotional experiences. Focus group interviews were selected as a method to collect data in an attempt to ensure that the process was not intimidating and that a stimulating space could be created for this emotional engagement, rather than one-on-one interviews (Madriz, 2003:365). Participant responses were allowed to dictate the flow of the conversation. Cohen, Manion and Morrison (2008:376) explain that the participant rather than the researcher's agenda should predominate because the interaction from the group during the interview will yield insights that 'might not otherwise have been available in a straightforward interview'. An audio recording was made of the focus 
group interview data and it was transcribed verbatim.

The data was inductively analysed. The transcripts were read and repeatedly examined. Conceptual themes and issues emerging from the data were identified. The technique of clustering, making comparisons and contrasts was applied (Miles \&Huberman, 1994).

Permission was obtained from the institution before the study commenced. Verbal as well as written consent to participate in the study was sought from all participants. Consent was also sought to have the focus group interview recorded. In service teachers were assured of confidentiality and anonymity.

\subsection{Findings and Discussion}

In an attempt to reflect on the DST process four NQT's experienced one year ago, a focus group interview was conducted to deliberate the process and its impact on their current teaching as well as their students' learning. While engaging in discussions using the pedagogy of vulnerability, NQT's understood that they would need to overstep boundaries which would render them vulnerable within their classroom community and with student engagement.

In the analysis of the data four themes became evident. They are:

- The teacher: facing our imperfections;

- Re-humanizing vulnerability;

- The lived curriculum and self-reflection; and

- Teaching and learning in the face of vulnerability

\subsubsection{The Teacher: Facing our Imperfections}

Excerpt 1

A discreet and cautious attitude started arousing my personality and character, such that I avoided to be seen by people. I had to deal with the assumptions people concluded about my life. No one had an idea what I was going through and no one showed interest as to why I was discreet and shy. I felt very vulnerable, even today as a young adult there are times I feel small and intimidated; I learnt to be independent at an early age because I knew that one day I will conquer the trial of poverty.

Facing our imperfections means letting go of who we think we should be and embracing who we really are. All four NQT's found it difficult to face their own imperfections during the DST process. Facing your imperfections translates into being vulnerable and this is very often coupled with feelings of fear, anxiety and frustration and has almost become synonymous with being weak. The pre-conceived thoughts are that in vulnerability you open yourself up to a host of criticism, to assumptions, to harm, to negative consequences. 'Walking into our stories of hurt', according to Brown (2017), 'can feel dangerous'. This is evident in the responses by all NQT's:

....she started the course, a lot of people... when they heard about the digital storytelling, I think that caused the most chaos in our class. Because I will say $85 \%$ of the people didn't want to do it at all and most of the times, I would speak to them, why don't you want to do it? For most of them it was fear...

I think the fear was from the judgement of peers...

... like you're scared because she tells us prior to the screening that your digital story will be watched by your fellow classmates, so now you're like, oh my God, now people are going to see my struggles...

However, it is in the midst of these struggles of facing our imperfections that we rise up, become courageous and regain our footing. These struggles may differ in magnitude, but as Brown (2017) articulates, 'We reckon with our emotions and get curious about what we're feeling; we rumble with our stories until we get to a place of truth; and we live this process, every day, until it becomes a practice and creates nothing short of a revolution in our lives'.

One NQT shared her revolutionised experience as:

'You get to look at yourself and look at the stereotypes..., the biases and the expectations that you have... it taught me to accept people as they come, so more especially when I started teaching... I can never judge the learner ... I don't know their situation... what the underlining issues are...'

Being vulnerable requires us to be brave and to trust. This results in reciprocity, giving birth to genuine connections being formed; connections which open doors to learning, learning in a safe space. 


\subsubsection{Re-Humanizing our Vulnerability}

Excerpt 2

Alcoholics supported my behavior because in my culture men must drink and marry. I was following the footsteps of my forefathers, and I should not be ashamed. Other relatives were against the strategy that I used to deal with my mother's death. Some had stereotypes about orphans; they believed that orphans end up being alcoholics and failures.

As days passed I realized my life was falling apart. I lost almost everything that my mother had left behind. Eventually I gave up alcohol and drugs and decided to go back to school. I managed to work for one year to get registered in tertiary education.

Now I'm doing my final year in Bachelor of education, and I'm going to be a teacher.

Another important theme that emerged from DST was that this experience became the tool with which students could critically engage with their own emotional trauma leaving most of them with the determination to succeed. 'Initial trauma and devastation....unites human beings... if we're allowed to talk openly about our collective grief and fear - if we turn to one another in a loving and vulnerable way, while at the same time seeking justice and accountability - it can be the start of the healing process' (Brown, 2017: 57).

However, in the absence of this opportunity to unite, because of vulnerability presenting itself in the form of 'stifling fear' as in the case below,

... how do I tell people that I was raped?... and she wrote a story... her digital story was on something that was not real, the real thing that she wanted to share with the class she never managed to say because the lecturer said, if you don't feel comfortable sharing your story, don't.

'We experience an emotional diversion away from the unravelling that's really happening in our homes and our communities' (Brown, 2017:57). Straka (2018) agrees and states that 'experiences of vulnerability are characterized by passivity, sensitivity and fragility', qualities that 'conjure up images of deficit'. These feelings of negativity respond to the 'dehumanizing circumstances' which result in 'low expectation'. However, vulnerability is a 'fundamental component of human experience' which contributes to further development in teacher resilience (Straka, 2018: 3).

For most of the NQT's their vulnerability became their greatest strength. Faced with opportunity to share emotional trauma gave the NQT in excerpt 2 the license to heal:

'it helped me to change the way I view the world because now I believe that every individual has something to tell...'.

Other NQT responses further justified:

'I think the process of the digital story telling makes you vulnerable but it also gives you strength because it's part of the healing process, ja.'

I gained a voice to share my experience ... OF ALL- I LEARNT THAT IT IS OKAY TO BE VULNERABLE FOR I KNOW I AM ENOUGH.

Re-humanizing vulnerability reveals strength and human capacity, leading ourselves and our learners to develop greater resilience and deeper learning.

\subsubsection{Lived Curriculum and Self-Reflection}

Excerpt 3

Personally I would say it is has changed the way that I view my learners. When I was starting with my teaching I would go on teaching practice and I used to have these expectations about children. But then I knew that they were different ... and I used to think but then if so and so can do it, why can't this child do it. It has taught me to be aware not everyone is cut from the same cloth. We are all different, we do things differently.

And I've managed to look at the child in a more holistic way ...

Findings in this study showed that reflecting on their own vulnerabilities translated into NQT's making their lived curriculum part of their classrooms. An almost natural part of the process for all NQT's was to reflect on their experiences, understanding how this translates into the lived curriculum and how the latter impacts their daily engagement with their colleagues and students. When reflecting on our own vulnerabilities we see, more vividly, the vulnerability of others. This is evident in the following responses:

It is an empowering process I would say because you get to, to question things. 
I think digital storytelling has taught me to be confident enough to educate my learners... that we are different we are all coming from different backgrounds. But we must not let our backgrounds be the barrier to our teaching and learning... So each person in the classroom has something that is bothering them... we are all human at the end of the day.

I think the process of the digital story telling gave me the confidence like to do self-introspection - so I reflect on whatever I do, like in my working environment, in the classroom, so I reflect and I try to treat people in a way that I would like to be treated, so I just tell myself, maybe that person is going through some stuff, so...

It is this DST experience that sowed the seeds of self-reflection, where 'learning becomes more relevant, has value beyond the classroom, and new meaning is constructed in the process' (Brantmeier, 2013). His substantiation reads: 'Share your story. If the educator opens her/his identity and life up for examination as part of the lived curriculum of the classroom, students will model that self-examination and go deeper in their learning'.

\subsubsection{Teaching and Learning in the Face of Vulnerability}

Excerpt 4

I think one thing that it has taught me is, to not judge my learners. The school that I'm at - most of the teachers say - oh but these children don't listen, don't even bother about them, ... but I opened up my classroom, not only for the learners that I teach, for the learners that are also coming from other classes. My class is always full, whether it's after school, ... we chat ... so at one stage one of the HOD's asked the learners, what do you like about being here? They said when we come to this class, we feel at home... They are not shy to come to talk to me about things, they come to me and they tell me about these things but when they talk to their own teachers, they are judged ... so I've got a lot of children in my class who come and sit, they just want to talk...

It was clear that all NQT's gained new insights around their learners and how they learn. It is evident from excerpt 4 that the DST process brought forth the realization that learning is more than just acquiring academic knowledge, it strengthens social engagement. Dunleavy \& Milton (2009) indicates that the literature connects social engagement and intellectual engagement and purports that

'When students have opportunities to connect with adults who approach these relationships with a spirit of caring, empathy, generosity, respect, reciprocity and a genuine desire to know students personally, they can make a unique contribution to young peoples' emerging adaptive capacity, self-sufficiency, resiliency, confidence, and knowledge of themselves as learners' (Dunleavy \& Milton, 2009: 15).

It was found that all NQT's appreciated the value of their lived experience and became more aware of the importance of the social interactions with their learners and how it impacted teaching and learning positively. Their responses below bears the evidence of this:

... it teaches us to understand others, when you transfer that understanding of the role of the digital story $\ldots$ it teaches us to understand our own learners.

... the digital story ... prepared me for my teaching profession,... a sort of awareness, I must be aware of my surroundings, ja. Secondly, looking at the staff... it prepares me that when you are looking at someone like you see the inner part of that particular person and the outer part ...

...when we were doing digital stories, we did not know that the guy that always likes to put on his headphones at the back of the classroom, is going through serious traumatic things, so it actually helped me to understand that people and even children go through a lot and that could be a barrier to teaching and learning.

'Just as teachers need safe spaces to process their vulnerability' (Straka, 2018) so too their learners need safe spaces to process theirs. Without strong social interaction between teachers and students, this vulnerability can 'prove to be a barrier to the creation of effective teacher-students interactions' (Brooks, 2008) - impacting learning negatively.

\section{CONCLUSION}

The objective of this study was to explore how the DST process impacted teacher vulnerability and consequently how it impacted teaching and learning in classroom settings. This study, set in a framework of a pedagogy of vulnerability, commenced with four NQT's experiencing the creation of their own personal 
stories which spoke to two themes viz: 'being human today' and 'colliding worldviews'. Limitations in the study include the following: a small sample of four NQT's provided the data and all the participants had completed their degrees at the same site/university. Access to literature, particularly around the concept of vulnerability also posed a limitation to this study.

While vulnerability is part of teaching, teachers manage it differently, and these differences have profound importance for:

- Teachers and their development

The experience of NQT's creating their own digital story forced them to accept their own imperfections, face their fears and anxieties, exposing themselves to critique and assumptions, yet emerging as stronger beings. Straka (2018:4) contends that our vulnerability is transformed into our strength and when we are ready to navigate those vulnerable episodes, those experiences will lead us to developing 'deep, meaningful connection with self and others. It is this connection that is central to our development as human beings'. The implementation of developing these deep meaningful connections will enhance teacher development and their pedagogy.

- Students and their learning

Overstepping the boundaries of vulnerability through personal disclosure led NQT's to understand the value of sharing and thus the importance of reciprocal exchanges with their students. They report that they now view their students through a different lens, a lens which re-humanizes vulnerability and understands that all students are vulnerable and should not be judged with assumption. Brooks (2008) purports that 'the assumptions teachers possess of themselves, their role as teachers and their students capabilities play a significant role in determining expectations, teaching practices and ultimately student success and happiness'.

- Teacher educators and their practice.

The DST process gave birth to a new appreciation of lived experience and self-reflection. NQT's questioned their perceptions of 'why', 'what' and 'how' they teach. They learnt the true value of social interaction and student engagement. The lesson: 'everyone experiences some challenges in life, and most have a story of their own journey through the tough times of life. The puzzle is that two people, who have experienced the same amount and intensity of adversity, and even the same exact event, can emerge differently' (Taylor \& Parsons, 2011).

Brinkmann (2010:83) contends 'one of the most important things a human being can learn is to see through acts of dehumanization and recognize vulnerable human beings as human beings'. The vulnerabilities experienced by all those who participate in the process of education are inherently threaded and becomes a powerful resource in the process of learning and connecting to ideas and to one another (Loveless, D.J. et al, 2016).

\section{REFERENCES}

Barret, H.C. 2005. Researching and evaluating digital storytelling as a deep learning tool. http://electronicportfolios.com/portfolios/SITEStorytelling2006.pdf. [20 June 2019].

Brantmeier, E.J. 2013. Pedagogy of vulnerability: definitions, assumptions and applications. In Lin, J. et al, Re-envisioning Higher Education: Embodied Pathways to Wisdom and Transformation. Information age forthcoming.

Brinkmann, S. 2010. Human vulnerabilities: Toward a theory of rights for qualitative researchers. Qualitative Inquiry and Human Rights, 82-99.

Brooks, R. and Goldstein, S., 2008. The mindset of teachers capable of fostering resilience in students. Canadian Journal of School Psychology, Vol. 23, No.1, pp 114-126.

Brown, B. 2017. Braving the wilderness: The quest for true belonging and the courage to stand alone. Penguin Random House, UK.

Brown, B. 2015. Daring greatly: How the courage to be vulnerable transforms the way we live, love, parent, and lead. Penguin Random House, UK.

Brookfield, S. 2004. The getting of wisdom: What critically reflective teaching is and why it's important. Retrieved from http://nlu.nl.edu/academics/cas/ace/facultypapters/StephenBrookfield.cfm. [21 June 2019].

Bullough, R. 2005. Teacher vulnerability and teachability: A case study of a mentor and two interns. Teacher Education Quartely, Vol. 32, No. 2, pp 23-29. 
Cohen, L. et al, 2008. Research methods in education. ( $7^{\text {th }}$ ed.). Routledge Falmer, London.

Condy, J. 2015. The construction and transformation of pre-service teacher's individual, social and professional identities during a Digital Storytelling module. In Condy, J. (ed). Telling stories differently: Engaging 21 st century students through digital storytelling. SUN MeDIA, Stellenbosch.

Delhey, J. et al, 2011. How general is trust in "most people"? Solving the radius of trust problem. American Sociological Review, Vol. 76, No. 5, pp 786-807.

Dewey, J. 1933. How we think: A restatement of the relation of reflective thinking to the educative process. Heath, Boston.

Dewey, J. 1989. The Later Works, vol. Boydston. University Press, Southern Illinois.

Digital Storytelling Association, 2002. The centre for digital storytelling. http://www.dsaweb.org/01associate/ds.html. [18 June 2019].

Dunleavy, J. \& Milton, P. 2009. What did you do in school today? Exploring the concept of Student Engagement and its implications for Teaching and Learning in Canada. Canadian Education Association (CEA), Toronto.

Forsyth, P. et al, 2011. Collective Trust: Why Schools Can't Improve Without It. Teachers College Press, New York.

Gachago, D. 2015. Seeing the world through somebody else's eyes: developing capabilities for a socially just education. In Condy, J. (ed).Telling stories differently: Engaging 21 st century students through digital storytelling. SUN MeDIA, Stellenbosch.

Hooks, B. 1994. Teaching to Transgress: Education as the Practice of Freedom. Routledge, New York.

Hooks, B. 2010.Teaching Critical Thinking: Practical Wisdom. Routledge, New York.

Kegan, R. 1982. The evolving self. Harvard University Press, Cambridge.

Kegan, R. 1995. In over our heads. Harvard University Press, Cambridge.

Keet, A. et al, 2009. Mutual vulnerability: a key principle in a humanizing pedagogy in post-conflict societies. Perspectives in Education, Vol. 27, pp 5-6.

Kelchtermans, G. 2009. Who I am in how I teach is the message: self-understanding, vulnerability and reflection. Teachers and Teaching: theory and practice, Vol. 15, No. 2, pp 257-272.

Lasky, S. 2005. A sociocultural approach to understanding teacher identity, agency and professional vulnerability in a context of secondary school reform. Teaching and Teacher Education, Vol. 21, No. 8, pp 899-916.

Loveless, D. J. et al, 2016. The vulnerability of teaching and learning in a selfie society. Sense Publishers, Rotterdam, Netherlands.

Madriz, E. 2003. Focus Groups in Feminist Research. Collecting and Interpreting Qualitative Materials. Sage, Thousand Oakes, California.

Mershon, K. 2018. A Pedagogy of Vulnerability: The Craft of Teaching in the Academic Study of Religion. https://craftofteachingreligion.wordpress.com/2018/10/22/a-pedagogy-of-vulnerability [23 June 2019].

Miles, M.G. and Hubermann, A.M. 1994. Qualitative data analysis. 2nd ed. Sage, Thousand Oaks, California.

Palmer, P. 1998. The courage to teach: Exploring the inner landscape of a teacher's life. Jossey-Bass, San Fransisco.

Robin, B. R. 2008. Digital storytelling: a powerful technology tool for the 21 st century classroom. Theory in practice, Vol. 47, pp 220-228.

Rodricks, D. 2018. Methodology as a Pedagogy of Vulnerability: Doctoral Research With/in/From the Borderlands. Qualitative Inquiry. 24. 107780041878810. 10.1177/1077800418788106

Rossiter, M. and Garcia, P.A. 2010. Digital Storytelling: A New Player on the Narrative Field. New Directions for Adult and Continuing Education, Vol. 126, pp 37-48.

Shandomo, H.M. 2010. The role of critical reflection in teacher education. School-University Partnerships, Vol. 4, No.1, pp 101-113.

Straka, A.L. 2018. Perception, permission and purpose: Portraits of vulnerability and resilience in teaching. Unpublished $\mathrm{PhD}$ thesis, University of Cincinnati, Cincinnati.

Squires, G. 1999.Teaching as a professional discipline. Falmer press, London, UK.

Taylor, L. \& Parsons, J. 2011. Improving Student Engagement. Current Issues in Education, Vol.14 No.1. Retrieved from http://cie.asu.edu/ [15 June 2019].

Turner, L. 2006. Renewing our genuineness in the classroom: Ways to become vulnerable again. Atlantic Universities Teaching Showcase 2005

$\mathrm{Xu}$, Y. et al, 2011. A new approach toward digital storytelling: an activity focused on writing self-efficacy in a virtual learning environment. Educational Technology and Society, Vol.14, No.4 pp 181-191.

Zembylas, M. 2011. The politics of trauma in education. Palgrave Macmillan, New York. 